\title{
Gastric conduit revision postesophagectomy: Management for a rare complication
}

\author{
Jessica Yu Rove, MD, ${ }^{\mathrm{a}}$ A. Sasha Krupnick, MD, ${ }^{\mathrm{a}}$ Frank A. Baciewicz, MD, ${ }^{\mathrm{b}}$ and \\ Bryan F. Meyers, MD, MPH
}

\section{ABSTRACT}

Objective: Severe postesophagectomy gastric conduit dysfunction refractory to standard endoscopic intervention is rare, with few published reports discussing timing, technique, or results of reoperation. This case series examines assessment and management of severe conduit dysfunction and details techniques for conduit revision.

Methods: We retrospectively reviewed patients who underwent esophagectomy between September 2008 and October 2015 and studied patients who underwent conduit revision.

Results: More than 400 patients underwent Ivor Lewis or transhiatal esophagectomies during this 7-year period. Eight patients underwent reoperation for conduit revision. The strategy for initial anastomosis and management of the pylorus were variable. Symptoms included dysphagia, delayed emptying, aspiration, and weight loss. Evaluation and management included esophagram, computed tomography, repeated esophagoscopy with pyloric intervention, and selective anastomotic dilation. Two patients also had associated paraconduit hiatal hernias. Average time to reoperation was 3.8 years (range 2 weeks to 6.5 years). All revisions were performed through a thoracotomy with either laparoscopy or laparotomy. Revisions were completed in 7 patients. Average length of stay was 9.9 days (range 4-21). Average follow up was 10.1 months (range 1-36). The completed revisions led to restoration of a regular diet with improved patient satisfaction.

Conclusions: Severe gastric conduit dysfunction after esophagectomy is rare. Symptoms, esophagram findings, and response to interventional esophagoscopy guide the decision to revise the conduit. Principles of conduit revision include reducing paraconduit hernias, reducing redundant conduit, tubularizing a dilated conduit, and ensuring adequate gastric drainage. Selective revision was performed with minimal morbidity and durable improvement in subjective symptoms of dysphagia and reflux. (J Thorac Cardiovasc Surg 2017;154:1450-8)



Esophagram (A) before and (B) after successful conduit revision with excellent emptying.

\section{Central Message}

In rare cases of severe conduit dysfunction, conduit revision can be performed selectively with minimal morbidity and durable symptom improvement.

\section{Perspective}

Severe postesophagectomy gastric conduit dysfunction is rare. Symptoms, imaging, and response to interventional esophagoscopy guide the decision to revise the conduit. Principles of revision include tubularization of redundant conduit and ensuring adequate gastric drainage. This case series outlines our management of conduit dysfunction and details techniques for conduit revision for symptom improvement.

See Editorial Commentaries pages 1459 and 1461.
Esophagectomy with reconstruction using a gastric conduit allows normal eating for many patients but produces significant gastrointestinal alterations. Delayed gastric emptying,

From the a Division of Cardiothoracic Surgery, Washington University, St. Louis, Mo; and ${ }^{\mathrm{b}}$ Division of Cardiothoracic Surgery, Wayne State University, Detroit Medical Center, Karmanos Cancer Center, Detroit, Mich.

Read at the 42nd Annual Meeting of the Western Thoracic Surgical Association, Waikoloa, Hawaii, June 22-25, 2016.

Received for publication June 30, 2016; revisions received March 31, 2017; accepted for publication April 4, 2017; available ahead of print May 16, 2017.

Address for reprints: Bryan F. Meyers, MD, MPH, Division of Cardiothoracic Surgery, Washington University, 660 S. Euclid Ave, Campus Box 8234, St. Louis, MO 63110 (E-mail: meyersb@wudosis.wustl.edu).

0022-5223/\$36.00

Copyright (c) 2017 by The American Association for Thoracic Surgery

http://dx.doi.org/10.1016/j.jtcvs.2017.04.012 gastric outlet obstruction, paraconduit hernias, and dumping syndrome are commonly observed complications of postesophagectomy. ${ }^{1-8}$ Of these, impaired gastric emptying is the most common, with as many as $15 \%$ to $30 \%$ of patients experiencing dysphagia, postprandial fullness, nausea, and reflux. In extreme cases, patients suffer from aspiration and weight loss.

Scanning this QR code will take you to the article title page. 
The initial management of these patients aims to improve gastric emptying with pyloric dilation or botulinum toxin injection to the pylorus. Although such treatments lead to symptom reduction in the majority of patients, up to $5 \%$ of patients have persistent symptoms of severe conduit dysfunction. ${ }^{4,8}$ Persistent symptoms in these patients can be associated with anatomic features such as a dilated and or redundant conduit, an inappropriately low esophagealgastric anastomosis that promotes reflux, and pyloric dysfunction with or without associated herniation of other abdominal contents such as colon or small bowel. Medications that promote gastric motility may improve conduit motility in the immediate, routine, postoperative period, but there are no long-term data demonstrating safety and effectiveness, and there is no evidence that such medications are therapeutic in late and difficult cases of severe conduit dysfunction. ${ }^{9,10}$ Datta and colleagues ${ }^{11}$ described rescue pyloroplasty alone to address refractory delayed gastric emptying postesophagectomy, but only 9 of $13(69 \%)$ patients had resolution of their symptoms. The implantation of gastric nerve stimulators has been proposed to address severe conduit dysfunction, but the application of this technology is limited and the durability is unknown. ${ }^{12,13}$

Surgical revision has been used to address anatomic features associated with severe conduit dysfunction. Kent and colleagues $^{8}$ described revision in 21 patients symptomatic with a redundant conduit. Through a combined thoracic and abdominal approach, the conduits were mobilized in the chest, reduced into the abdomen, and sutured to the diaphragm. All but $2(9 \%)$ revisional operations were completed minimally invasively with a success rate of $65 \%$. A more extensive surgical approach that uses Rouxen-Y reconstruction has been described to address reflux esophagitis both preemptively, as a primary reconstructive technique, and in the reoperative setting. ${ }^{14,15}$ D'Journo and colleagues ${ }^{14}$ described a small series of 4 patients who underwent conversion of a standard gastric conduit to a Roux-en-Y reconstruction for severe conduit dysfunction. Only 2 of 4 $(50 \%)$ patients had resolution of symptoms despite the drawbacks of significant morbidity and length of stay. ${ }^{14,15}$

Literature is sparse on how to best address severe postesophagectomy conduit dysfunction. Uncertainty exists regarding when and how to intervene, if and when to reoperate, and ultimately what operation to perform. This case series aims to share experiences and stimulate investigation by discussing the assessment and management of severe conduit dysfunction after esophagectomy and detailing our techniques for conduit revision for symptom relief.

\section{METHODS \\ Patient Selection}

We retrospectively reviewed patients who underwent conduit revision between September 2008 and October 2015 at our institutions. Washington University's Institutional Review Board approved the study. We excluded patients who underwent isolated repair of paraconduit hernias in the presence of an adequately performing gastric pull-up.

\section{Esophagectomy Technique}

Patients underwent the workup appropriate for their diagnosis. In the setting of esophageal cancer, diagnosis, staging, and neoadjuvant therapy followed guidelines outlined by the Society of Thoracic Surgeons and National Comprehensive Cancer Network. ${ }^{16,17}$ Both open and minimally invasive transhiatal and Ivor Lewis esophagectomies were performed during the study period. Treatment of the pylorus varied by surgeon, ranging from no treatment to botulinum toxin injection, pyloroplasty, or pyloromyotomy. The gastric conduit was tubularized to a width of 4 to $5 \mathrm{~cm}$. The diaphragmatic crura were not reapproximated routinely after the esophagus was mobilized. The abdominal portion of the conduit was not tacked routinely to the diaphragm.

\section{Initial Management}

Postesophagectomy patients were followed in thoracic surgery clinic by the operating surgeon. Computed tomography scans were performed for oncologic surveillance in patients with a diagnosis of esophageal cancer. Symptoms suggestive of conduit dysfunction were evaluated in a stepwise manner but not according to any predetermined protocol. Flexible esophagoscopy commonly was performed to assess the presence of an anastomotic stenosis, retained food in the conduit, pyloric stenosis, and mucosal abnormalities such as anastomotic ulcer or recurrent cancer. Suspected gastric outlet obstruction was addressed with pneumatic dilation of the pylorus to $20 \mathrm{~mm}$, the rare use of botulinum toxin injection 200 units in $8 \mathrm{~mL}$ total divided into 4 quadrants, or both. If a tight anastomosis was a concern, pneumatic dilation of the anastomosis also was performed. For patients with persistent symptoms despite dilation procedures, additional imaging was pursued. An esophagram often was obtained to assess conduit dynamics and shape, location of the pylorus, and the speed of emptying into the duodenum. Computed tomography of the chest, abdomen, and pelvis was obtained to evaluate the remainder of the anatomy around the reconstruction and any extrinsic factors that may be contributing to symptoms.

Conduit revision was indicated for patients with persistent symptoms refractory to initial management strategies and anatomic features amenable to surgical correction such as a dilated and or redundant conduit, a relatively low and or stenotic esophageal-gastric anastomosis, with or without an associated paraconduit hernia. Specific risks discussed with the patients preoperatively included but were not limited to bleeding, infection, pain, recurrent or persistent symptoms, enteric leak, chyle leak, phrenic nerve injury, aspiration, and conduit injury that could require a subsequent staged surgery to maintain the ability to eat. Nutrition was optimized before elective conduit revision, and patients completed antibiotics as indicated for aspiration pneumonia.

\section{Surgical Technique}

Patients were encouraged to have a thoracic epidural for analgesia. General anesthesia was administered, and patients were intubated with a double-lumen tube. Special care was taken to minimize the risk of aspiration on induction. Fiberoptic esophagoscopy was performed to empty the redundant conduit. All reoperations in this series started in the chest with a posterolateral thoracotomy either left or right. Bilateral posterolateral thoracotomies were performed rarely to safely mobilize the conduit. Attempts were made to reuse previous thoracotomy incisions. The inferior rib was shingled frequently to improve exposure. The conduit was mobilized from the anastomosis to the diaphragm, with care taken to avoid injury to the conduit blood supply and the phrenic nerve. Associated transverse colon hernias were dissected free and reduced. If indicated, the esophagogastric anastomosis was revised with an end-to-end anastomosis 
TABLE 1. Details for each index operation and subsequent revision, including initial management, timing of reoperation, and surgical technique

\begin{tabular}{|c|c|c|c|c|c|c|c|c|c|c|c|}
\hline \multirow[b]{2}{*}{ Patient } & \multirow[b]{2}{*}{ Diagnosis } & \multicolumn{8}{|c|}{ Index esophagectomy } & \multirow[b]{2}{*}{$\begin{array}{c}\text { Gastric } \\
\text { drainage }\end{array}$} & \multirow{2}{*}{$\begin{array}{c}\text { Conduit revision } \\
\\
\text { Postesophagectomy } \\
\text { symptoms }\end{array}$} \\
\hline & & Age, $y$ & $\mathbf{M} / \mathbf{F}$ & Path & $\begin{array}{c}\text { Date of } \\
\text { Surgery }\end{array}$ & OSH & Operation & $\begin{array}{l}\text { R/L VATS/ } \\
\text { Open }\end{array}$ & $\begin{array}{l}\text { Lap/ } \\
\text { Open }\end{array}$ & & \\
\hline 1 & $\begin{array}{l}\text { Parathyroid } \\
\text { cancer } \\
\text { metastatic to } \\
\text { esophagus }\end{array}$ & 59 & $\mathrm{M}$ & $\begin{array}{l}\text { 9.5-cm parathyroid } \\
\text { cancer invading } \\
\text { trachea, esophagus, } \\
\mathrm{L} \text { thyroid and } \\
\text { recurrent laryngeal } \\
\text { nerve }\end{array}$ & $9 / 2008$ & & $\begin{array}{l}\text { Cervical exenteration } \\
\text { (laryngectomy, } \\
\text { pharyngectomy, } \\
\text { esophagectomy, } \\
\text { thyroidectomy, } \\
\text { parathyroidectomy, } \\
\text { manubrium } \\
\text { resection, resection } \\
\text { of medial clavicles) } \\
\text { gastric pull-up with } \\
\text { cervical } \\
\text { anastomosis, } \\
\text { pyloroplasty }\end{array}$ & N/A & Open & Pyloroplasty & $\begin{array}{l}\text { Impaired gastric } \\
\text { emptying, weight } \\
\text { loss }\end{array}$ \\
\hline 2 & Leiomyoma & 49 & $\mathrm{M}$ & Unknown & $1 / 2009$ & $\mathrm{OSH}$ & $\begin{array}{l}\text { Distal esophagectomy: } \\
\text { stapled side to side, } \\
\text { unknown pylorus } \\
\text { treatment }\end{array}$ & L posterolateral & Open & No & Reflux \\
\hline 3 & $\begin{array}{l}\text { Esophageal } \\
\text { cancer }\end{array}$ & 51 & M & $\begin{array}{l}\text { Barrett's esophagus } \\
\text { with high-grade } \\
\text { dysplasia, } 0 / 23 \\
\text { nodes }\end{array}$ & $7 / 2009$ & & $\begin{array}{l}\text { Ivor-Lewis, } \\
\text { pyloromyotomy, } \\
\text { 28-mm EEA }\end{array}$ & $\mathrm{R}$ posterolateral & Open & Pyloromyotomy & Fullness, dysphagia \\
\hline 4 & $\begin{array}{l}\text { Esophageal } \\
\text { cancer }\end{array}$ & 62 & M & $\mathrm{T} 2 \mathrm{~N} 1$ adenocarcinoma & $10 / 2009$ & & $\begin{array}{l}\text { Ivor-Lewis, no pyloric } \\
\text { intervention, 28-mm } \\
\text { EEA }\end{array}$ & $\mathrm{R}$ posterolateral & Open & No & Dysphagia \\
\hline 5 & $\begin{array}{l}\text { Esophageal } \\
\text { cancer }\end{array}$ & 51 & $\mathrm{~F}$ & $\mathrm{~T} 2 \mathrm{~N} 0$ adenocarcinoma & $2 / 2011$ & & $\begin{array}{l}\text { Ivor-Lewis, no pyloric } \\
\text { intervention, 28-mm } \\
\text { EEA }\end{array}$ & R VATS & Lap & No & $\begin{array}{l}\text { Dysphagia, emesis, } \\
\text { weight loss }\end{array}$ \\
\hline
\end{tabular}

\begin{tabular}{|c|c|c|c|c|c|c|c|c|c|c|}
\hline 6 & $\begin{array}{l}\text { Esophageal } \\
\text { perforation, } \\
\text { failed Nissen } \\
\text { fundoplication }\end{array}$ & 35 & M & Chronic gastritis & $8 / 2012$ & $\begin{array}{l}\text { Ivor-Lewis with Botox } \\
\text { to pylorus, hand- } \\
\text { sewn anastomosis }\end{array}$ & $\mathrm{R}$ posterolateral & Open & Botox & Dysphagia \\
\hline 7 & $\begin{array}{c}\text { Esophageal } \\
\text { cancer }\end{array}$ & 44 & M & $\mathrm{T} 3 \mathrm{~N} 0$ adenocarcinoma & $6 / 2012$ & $\begin{array}{l}\text { Ivor-Lewis with Botox } \\
\text { to pylorus, stapled } \\
\text { side-to-side } \\
\text { anastomosis }\end{array}$ & R VATS & Lap & Botox & Dysphagia, nausea \\
\hline 8 & $\begin{array}{c}\text { Esophageal } \\
\text { cancer }\end{array}$ & 73 & M & $\mathrm{T} 2 \mathrm{~N} 0$ adenocarcinoma & $11 / 2012$ & $\begin{array}{l}\text { Ivor-Lewis with Botox } \\
\text { to pylorus, 28-mm } \\
\text { EEA }\end{array}$ & $\mathrm{R}$ posterolateral & Open & Botox & $\begin{array}{l}\text { Dysphagia, } \\
\text { aspiration, } \\
\text { weight loss }\end{array}$ \\
\hline
\end{tabular}

$M$, Male; $F$, female; $O S H$, outside hospital not associated with this study; $R / L$, right/left; VATS, video-assisted thoracoscopic surgery; Lap, laparoscopy; $L O S$, length of stay; $L$, left; N/A, not applicable; $C T$, computed tomography; FOE, fiberoptic esophagoscopy; $P D$, pyloric dilation to $20 \mathrm{~mm}$; Botox, 4-quadrant botulinum injection to pylorus, total of 200 units in $8 \mathrm{~mL} ; J$ tube, jejunostomy tube; $E E A$, end-to-end anastomosis; $A D$, anastomotic dilation to $20 \mathrm{~mm} ; R$, right. 


\begin{tabular}{|c|c|c|c|c|c|c|c|c|c|}
\hline \multicolumn{10}{|c|}{ Conduit revision } \\
\hline Features & $\begin{array}{c}\text { Initial } \\
\text { management }\end{array}$ & $\begin{array}{c}\text { Years } \\
\text { between } \\
\text { index } \\
\text { operation } \\
\text { and revision }\end{array}$ & $\begin{array}{l}\text { Age at } \\
\text { Revision }\end{array}$ & Operation & $\begin{array}{c}\text { R/L } \\
\text { VATS/open }\end{array}$ & $\begin{array}{c}\text { Laparoscopy/ } \\
\text { open }\end{array}$ & $\begin{array}{c}\text { Gastric } \\
\text { drainage }\end{array}$ & Complications & $\begin{array}{l}\text { LOS, } \\
\text { days }\end{array}$ \\
\hline $\begin{array}{l}\text { Missed L liver mass } \\
\text { compressing conduit } \\
\text { change in } \\
\text { appearance from } \\
2012 \text { to } 2015 \text { on CT } \\
\text { scan }\end{array}$ & $\begin{array}{l}\text { 7/2010 - FOE PD } \\
\text { 7/2011 - FOE tortuous } \\
\text { conduit } \\
\text { 1/2015 - FOE PD } \\
\text { Botox }\end{array}$ & 6.5 & 65 & $\begin{array}{c}\text { Mobilization of } \\
\text { intrathoracic } \\
\text { conduit, liver } \\
\text { biopsy, J tube }\end{array}$ & L posterolateral & Open & N/A & None & 9 \\
\hline $\begin{array}{l}\text { Distended conduit, } \\
\text { delayed emptying } \\
\text { ( } 380 \mathrm{~min}) \text {, reflux, } \\
\text { esophagogastric } \\
\text { junction at } 30 \mathrm{~cm} \text {, } \\
\text { crura at } 40 \mathrm{~cm}\end{array}$ & 1/2015 - FOE & 6 & 55 & $\begin{array}{l}\text { Ivor-Lewis, 25-mm } \\
\text { EEA, pyloroplasty }\end{array}$ & Bilateral & Open & Pyloroplasty & $\begin{array}{l}\text { PD AD } 1 \text { mo } \\
\text { postoperatively }\end{array}$ & 14 \\
\hline $\begin{array}{l}\text { Redundant conduit, } \\
\text { colon hernia }\end{array}$ & $\begin{array}{l}\text { 3/2013 - FOE, no } \\
\text { stricture, } 60-\mathrm{F} \\
\text { bougie passed easily }\end{array}$ & 4.5 & 55 & $\begin{array}{l}\text { Conduit plication } \\
\text { stitches, reduce } \\
\text { colon }\end{array}$ & $\mathrm{R}$ posterolateral & Laparoscopy & N/A & None & 7 \\
\hline Dilated conduit & $\begin{array}{l}\text { 12/2009 - FOE PD } \\
\text { 6/2010 - FOE PD } \\
\text { Botox }\end{array}$ & 1 & 63 & $\begin{array}{l}\text { Stapled conduit } \\
\text { revision and EEA } \\
\text { (not specified), R } \\
\text { lung decortication }\end{array}$ & $\mathrm{R}$ posterolateral & N/A & No & None & 9 \\
\hline Dilated conduit & $\begin{array}{l}\text { 2/2011 - FOE Botox } \\
\text { 3/2011 - FOE PD AD } \\
\text { 4/2011 - FOE PD AD } \\
\text { 8/2011 - FOE PD } \\
\text { 1/2012 - FOE PD AD } \\
\text { and Botox } \\
\text { 3/2012 - FOE PD AD } \\
\text { 6/2012 - FOE PD and } \\
\text { Botox } \\
\text { 8/2014 - FOE PD and } \\
\text { Botox } \\
\text { 5/2015 - FOE PD and } \\
\text { Botox }\end{array}$ & 4.5 & 55 & $\begin{array}{l}\text { Conduit plication } \\
\text { stitches, } \\
\text { pyloroplasty, J tube }\end{array}$ & $\mathrm{R}$ posterolateral & Open & Pyloroplasty & None & 11 \\
\hline Dilated conduit & $\begin{array}{l}\text { 10/2012 - FOE PD } \\
\text { 10/2013 - FOE PD } \\
\text { gastric lavage with } \\
\text { Ewald tube } \\
\text { 4/2014 - FOE PD } \\
\text { 7/2014 - FOE PD } \\
\text { 9/2014 - FOE PD } \\
\text { 5/2015 - FOE PD }\end{array}$ & 2.8 & 38 & $\begin{array}{l}\text { Stapled conduit } \\
\text { revision, 28-mm } \\
\text { EEA }\end{array}$ & $\mathrm{R}$ posterolateral & N/A & No & $\begin{array}{l}\text { Contained leak at } \\
\text { EEA requiring J } \\
\text { tube placement, } \\
\text { dysphagia }\end{array}$ & 21 \\
\hline $\begin{array}{l}\text { Redundant conduit, } \\
\text { colon hernia }\end{array}$ & 7/2012 - FOE PD & $2 \mathrm{wk}$ & 44 & $\begin{array}{l}\text { Stapled conduit } \\
\text { revision, 25-mm } \\
\text { EEA, reduce colon, } \\
\text { retrograde drain }\end{array}$ & $\mathrm{R}$ posterolateral & Open & No & None & 4 \\
\hline Redundant conduit & $\begin{array}{l}\text { 8/2013 - FOE PD } \\
\text { Botox }\end{array}$ & 1 & 74 & $\begin{array}{l}\text { Conduit plication } \\
\text { stitches, } \\
\text { pyloroplasty }\end{array}$ & $\mathrm{R}$ posterolateral & Open & Pyloroplasty & None & 4 \\
\hline
\end{tabular}


stapler at the level of the azygos vein or preferably higher. The necessity of revising the anastomosis was based on the surgeon's judgment at the time of surgery. Dilated conduit (excessive diameter and volume) was revised with a series of plication stitches using 2-0 silk or with a stapler along the lesser curvature to create a tube approximately 4 to $5 \mathrm{~cm}$ in width. The conduit revision was inspected with fiberoptic esophagoscopy.

To complete the revision, many patients were repositioned supine, and a laparotomy or laparoscopy was performed. Paraconduit hernias were reduced and repaired. Redundant conduit (excessive length in the chest) was reduced back into the abdomen with the goal of straightening out the conduit without putting the reconstruction under tension. Frequently, a few tacking stitches were placed between conduit and the crura. A pyloroplasty often was performed to improve gastric drainage. Placement of a jejunal feeding tube was performed selectively at the discretion of the surgeon, with or without a percutaneous retrograde gastric drain. ${ }^{18}$

Patients were admitted postoperatively to either the thoracic step-down unit or intensive care unit, then transferred to the floor when appropriate. An esophagram was obtained on the seventh postoperative day. No oral intake was initiated until after there was no clinical or radiographic evidence of an enteric leak.

Patients were followed up in clinic at 1 month from their operation. A successful revision was determined subjectively by the patient describing symptoms and objectively by recording the patient's diet and weight.

\section{RESULTS}

During the 7-year study period, 8 patients underwent reoperation for conduit revision. Average patient age at the revision operation was 56 years (range 38-74 years), and 7 of the 8 patients were men. Six patients had an Ivor Lewis esophagectomy at their original operation, one had a transhiatal esophagectomy, and one had a distal esophagectomy with gastric pull-up. The type of initial anastomosis and management of the pylorus were variable (Table 1). Four patients had a stapled end-to-end anastomosis anastomosis, 2 patients had a stapled side-to-side anastomosis, and 2 had a hand-sewn anastomosis.

Postesophagectomy symptoms of conduit dysfunction included nausea, dysphagia, reflux with or without aspiration, and or weight loss. All patients experienced at least one fiberoptic esophagoscopy with pyloric dilation and selective anastomotic dilation (average 3.3, range 1-9 esophagoscopies per patient). Prerevision contrast imaging demonstrated some consistent anatomic characteristics (Figures 1-3). The conduits tended to be distended, with poor emptying and air-fluid levels. Some appeared to take a more horizontal rather than vertical course through the chest, leading to a relatively acute angulation of the conduit at the diaphragm. Specifically, patients 4,6 , and 7 underwent revision of their esophagogastric anastomosis, bringing it more proximal in the chest, thus straightening the conduit in the thorax. Two patients had associated paraconduit colon hernias. Average time from esophagectomy to reoperation was 3.8 years (range 2 weeks to 6.5 years). All revisions included a thoracotomy. Six patients had a right thoracotomy, one patient had a left thoracotomy, and one patient had bilateral thoracotomies. In 2 patients, no abdominal revision was required, one patient had a laparoscopic abdominal revision, and the remainder underwent a laparotomy. Revision was completed successfully in 7 patients. One patient had a liver mass, a recurrent tumor from the initial cancer that was not appreciated preoperatively. In this patient, the conduit revision was abandoned when liver biopsy demonstrated malignancy and a feeding jejunostomy tube was placed. There were 2 complications: one patient had a contained leak at the revised esophagogastric anastomosis requiring temporary jejunostomy tube placement and one patient required balloon dilation of the anastomosis and pylorus 1 month postrevision. The average length of stay was 9.9 days (range 4-21). An esophagram was performed postrevision, before we initiated a diet and discharged the patient from the hospital (Figures 1 and 2). The average follow-up was 10.1 months (range 1-36). All 7 patients with completed revisions reported symptom improvement and returned to eating a regular diet.

\section{DISCUSSION}

Severe gastric conduit dysfunction after esophagectomy can be defined by symptoms not relieved with interventional endoscopy. Our case series suggests that this complication is rare. It is beyond the scope of this small article to speculate on the specific factors leading to this very rare complication. However, we demonstrate that in some patients, symptoms of severe conduit dysfunction are associated with multiple anatomic abnormalities that can be addressed surgically. Patient 2 had a conduit that had dilated with time, was poorly functioning with documented delayed gastric emptying, and a relatively low esophagogastric anastomosis located at $30 \mathrm{~cm}$. Two patients had redundant conduits as well as paraconduit hernias. Patients 4 and 6 had conduits that were both dilated and redundant. The air fluid level such as the one seen in Figure 1 is evidence of poor motility. In all patients who underwent multiple pyloric dilations, transient symptom relief with pyloric dilation indicates some contribution of pyloric stenosis to their symptoms. These multiple anatomic abnormalities warrant a comprehensive revisional approach that we propose has several parts: optimize the level of the anastomosis and revise a stenotic anastomosis in the chest, narrow a dilated conduit, straighten an angulated conduit, reduce associated paraconduit hernias, and ensure adequate gastric drainage.

Ensuring adequate gastric drainage is deliberately subjective. The utility of surgical pyloric drainage at the time of esophagectomy is debated actively in the literature. ${ }^{19}$ Our current practice has evolved to using botulinum injection at the time of the initial esophagectomy. In our series, 6 patients did not have surgical pyloric drainage at the time of their esophagectomy. At the time of their revision, 3 underwent pyloroplasty, 3 did not have any pyloric intervention, and 1 patient from each group underwent a single postrevision pyloric dilation for symptoms of dysphagia. 

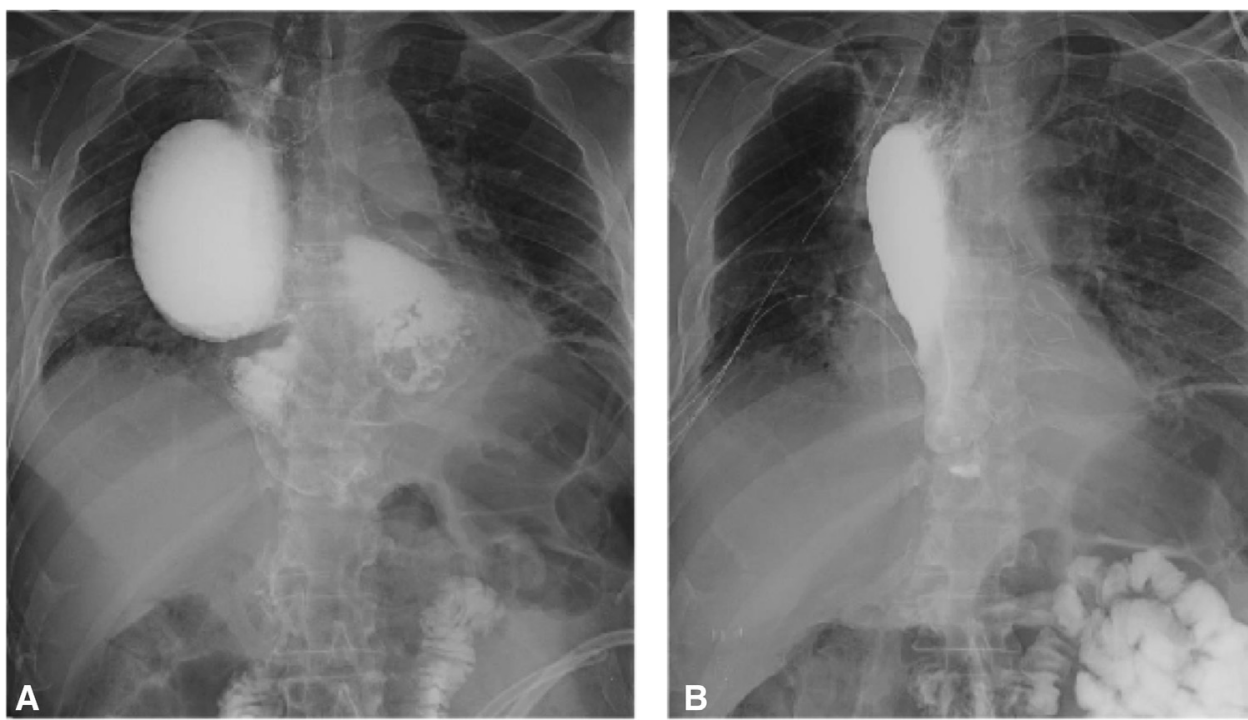

FIGURE 1. Patient 4 status post-Ivor Lewis esophagectomy with delayed gastric emptying and reflux despite repeated pyloric dilation and botulinum injections. A, Prerevision esophagram demonstrating a dilated and redundant gastric conduit. B, Same patient after revision of his esophagogastric anastomosis and stapled reduction of their conduit.

The patient who required anastomotic and pyloric dilation 1 month postrevision has not required any subsequent interventions. The patient who experienced a contained leak and required jejunostomy placement underwent esophagoscopy and pyloric dilation for symptoms of dysphagia one time, 8 months postrevision. His anastomosis appeared patent without stenosis.

Endoscopic pyloric interventions are a typical initial management strategy for postesophagectomy conduit dysfunction. The timing of when patients present with postesophagectomy gastric conduit dysfunction is variable. As evidenced by the time lapse between the date of their esophagectomy and the date of their first pyloric dilation in Table 1 , some patients manage for years before developing significant symptoms. Others develop symptoms within weeks or months of their operation. The incidence of severe conduit dysfunction refractory to balloon dilation or botulinum toxin injection seems to range between 0 and $5 \%$ in published series. In a retrospective study of more than $700 \mathrm{elec}-$ tive esophagectomies with $60 \%$ undergoing a gastric drainage procedure during initial esophagectomy, Datta and colleagues reported a $22 \%$ incidence of primary postoperative delayed gastric emptying leading to endoscopic balloon dilation and severe conduit dysfunction with symptoms refractory to those interventions in only $1.6 \%$ of patients. ${ }^{11}$

Lanuti and colleagues ${ }^{4}$ presented a series with 436 esophagectomies using a variety of techniques, with one half undergoing gastric drainage procedures at the index operation. Postoperative gastric outlet obstruction occurred in $22 \%$ (98 of 436). Treatment options were observation, administration of prokinetics, nasogastric tube drainage, and endoscopic balloon dilation. An average of 1.7 (range 15) pyloric dilations successfully treated gastric outlet obstruction in all but $5 \%$ ( 2 of 38 patients), with $87 \%$ of dilations occurring within 4 months from esophagectomy. The 2 patients with severe conduit dysfunction were managed with operative intervention, one with a rescue pyloroplasty and the other with a Roux-Y reconstruction.

Eldaif and colleagues ${ }^{2}$ reported a series of more than 300 patients who underwent gastric drainage procedures (botulinum, pyloromyotomy, or pyloroplasty) during the index esophagectomies with a $12 \%$ incidence of delayed gastric emptying and $6 \%$ of patients requiring dilation of the pylorus by 6 months. In a retrospective review of more than 400 patients undergoing Ivor Lewis esophagectomy with tubular conduit reconstruction, Maus and colleagues ${ }^{1}$ reported that after patients underwent one balloon dilation, about $30 \%$ needed a subsequent dilation up to a maximum of 4 . These studies mirror our aggressive use of interventional endoscopy for initial management of postesophagectomy conduit dysfunction.

A subset of patients who receive multiple dilations experience temporary, but not durable, improvement. When this initial management strategy fails to control symptoms of dysphagia, reflux, and aspiration, an operative approach can be considered. The number of dilations (Table 1) before revisional surgery reflect both surgeon and patient readiness to proceed with a reoperation. Consideration is made of the initial pathology report and the time since the initial therapy, because a high fraction of patients with locally advanced esophageal cancer will succumb to recurrent disease, frequently in the first 2 years since treatment. Esophagram and computed tomography 

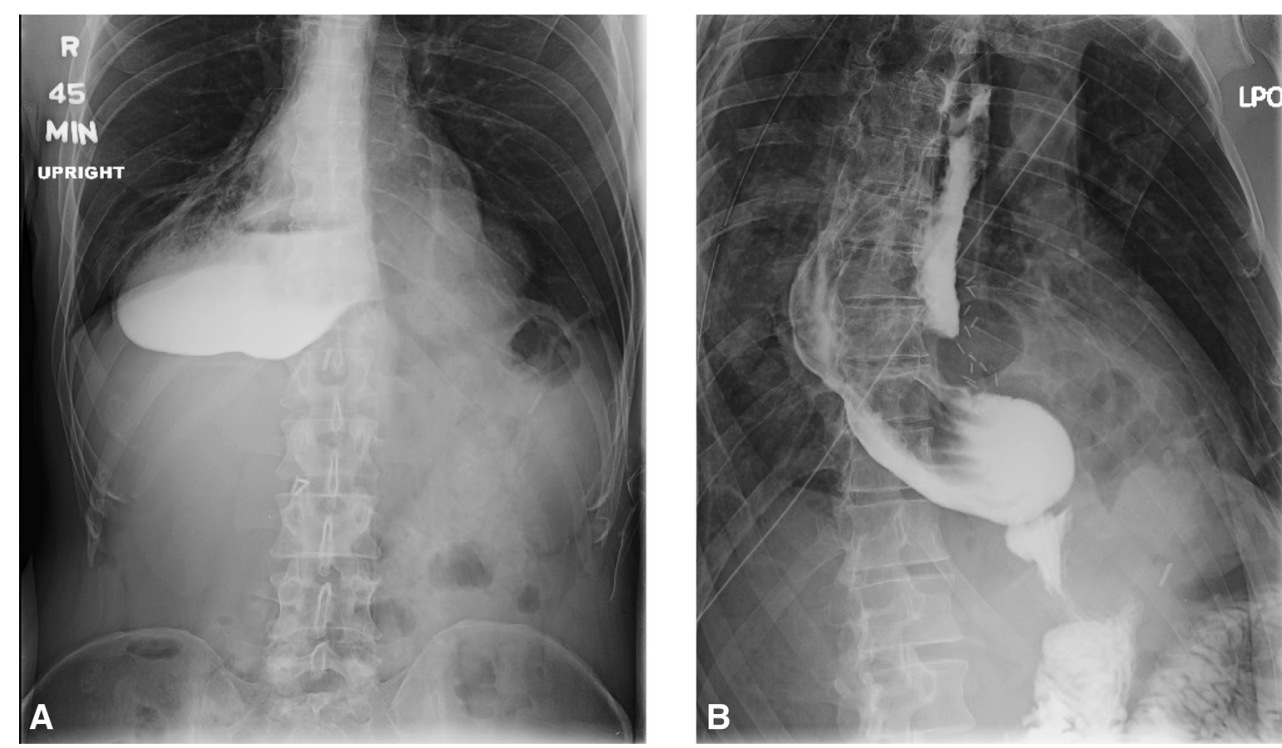

FIGURE 2. Patient 6 status post-Ivor Lewis esophagectomy with a prerevision esophagram (A) illustrating a distended conduit with an air-fluid level. He had poor emptying 45 minutes after the initiation of the study despite repeated pyloric dilation. B, This patient underwent revision of his esophagogastric anastomosis and stapled revision of the conduit with a postrevision esophagram, demonstrating a more tubular and vertical conduit with improved emptying. $L P O$, Left posterior oblique.

imaging at this juncture are critical. One of our patients presented with obstructive symptoms and an esophagram consistent with delayed gastric emptying and had been treated with 3 endoscopic procedures including pyloric dilation and botulinum injection. His reoperation was attempted 6.5 years from his index esophagectomy and, intraoperatively, he was found to have a large liver metastasis causing extrinsic compression of his conduit (Figure 3). Computed tomography imaging evaluates the remaining anatomy in the chest and abdomen that may
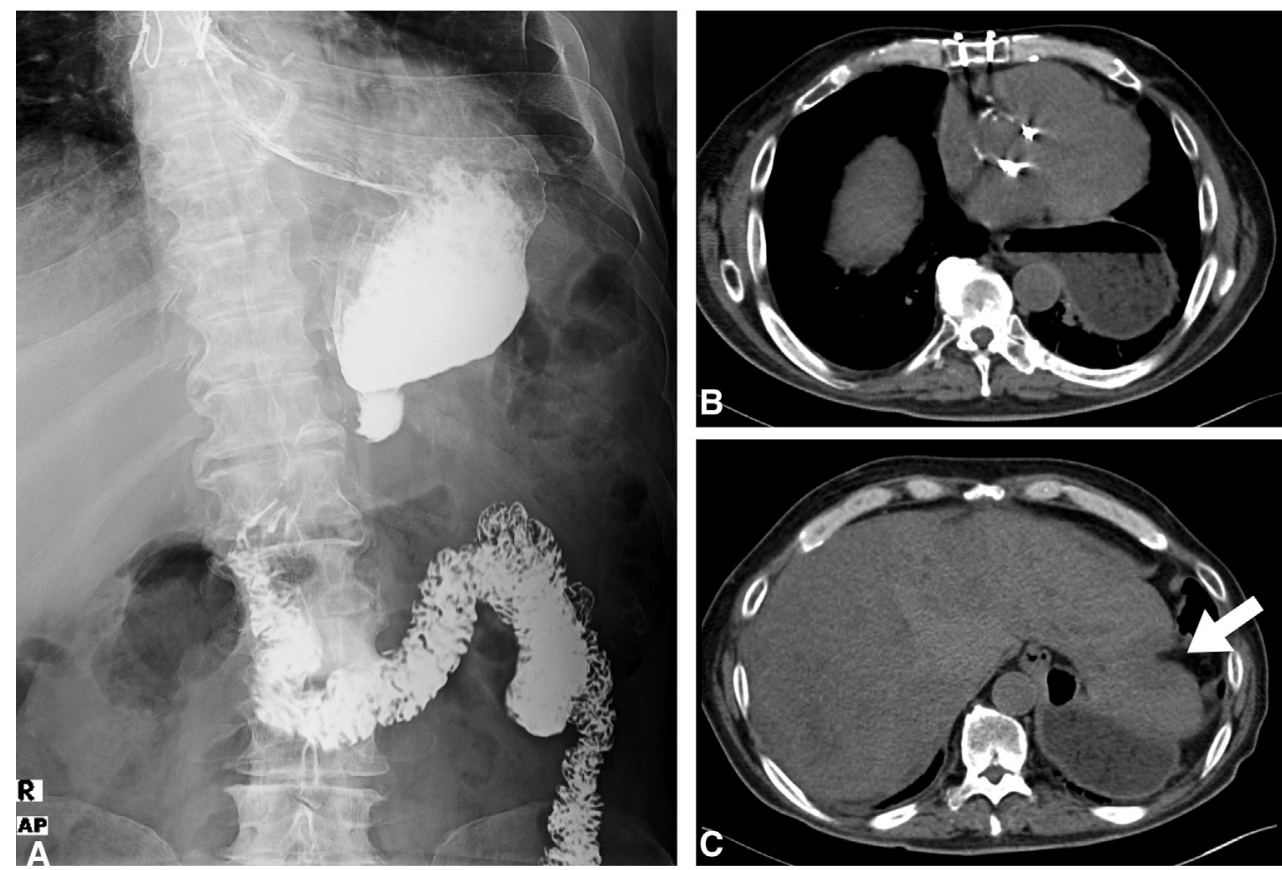

FIGURE 3. Patient 1 status post-transhiatal esophagectomy was evaluated for revision 6.5 years after his original operation. A, Prerevision esophagram shows a conduit that starts midline then acutely angles into the left hemithorax. B, Computed tomography image shows the air-fluid level in the distended conduit in the left chest. C, This left liver mass (white arrow) compressing the conduit as it enters the abdomen was not appreciated before the attempted revision. Conduit revision was aborted for liver biopsy and jejunostomy tube placement. 
be contributing to symptoms, such as the location of the esophagogastric anastomosis in the chest, metastatic disease, or a paraconduit hernia.

The decision to revise the esophagogastric anastomosis at the time of the revision is determined by (1) the location of the anastomosis and (2) whether there is a concern for stenosis at the anastomosis. The authors have a preference for an anastomosis that is $25 \mathrm{~cm}$ from the incisors or higher, so the degree to which that mark is missed in a symptomatic patient with conduit dysfunction will guide the decision about revising the anastomosis. Thoracic mechanics dictate that the negative pressure generated by inhalation can worsen reflux, particularly if the anastomosis is in the lower half of the chest and there is fluid filled stomach straddling the hiatus. The decision to tubularize and narrow a dilated conduit is based on multiple studies indicating that, compared with using the whole stomach for reconstruction, a partial gastric tube correlates with better quality of life and reflux scores. ${ }^{19-21}$ Repairing associated paraconduit hernias is not without potential morbidity; however, in the setting of conduit revision we feel that the presence of a paraconduit hernia may worsen symptoms of dysphagia and fullness. ${ }^{5-7}$ A singular retrospective study addresses rescue pyloroplasty alone in 13 patients with refractory delayed gastric emptying postesophagectomy. ${ }^{11}$ Although the data on performing gastric drainage at the initial esophagectomy are mixed, in the setting of severe gastric conduit dysfunction like that in the patients we have reported here, we feel that ensuring adequate gastric drainage outweighs the risk of allowing symptomatic bile reflux and mucosal changes.

Our series used a combined thoracic and abdominal approach that we feel is critical for a successful revision. We agree with the study by Kent and colleagues ${ }^{8}$ that the thoracic exposure is essential for full mobilization of the conduit. Although some centers have described a minimally invasive approach to gastric conduit revision with limited success, in our hands, we have demonstrated that a selective and open approach has yielded excellent results with minimal morbidity and no mortality.

Another alternative to our adopted strategy of conduit revision may be a Roux-en-Y reconstruction. ${ }^{4,14}$ D'Journo and colleagues ${ }^{14}$ described 4 revision surgeries for reflux into the conduit with or without associated gastroparesis. All 4 patients received a Roux-en-Y reconstruction between 2 and 11 years from the original operation. Only one anastomosis had to be revised and that was due to a gastrobronchial fistula. ${ }^{14}$ Although this reconstruction does comprehensively address the anatomic components that contribute to symptoms of dysphagia and reflux, it is more complex and potentially morbid in a reoperative setting. Finally, colon interposition or the so-called "supercharged jejunum" seem appropriate when stomach is not available, but those strategies seem heavy-handed when the stomach is available but simply needs revision.
There are several limitations to our study. First and foremost, severe conduit dysfunction is extremely rare; thus, we are limited to a small number of patients studied in a retrospective manner. This is not a trial, and there was not a protocol that was followed. These patients represent routine clinical care, and the decisions made were the best options available at the time they were chosen. In addition, this study cannot attempt to answer questions about how best to prevent severe conduit dysfunction. The systematic review by Akkerman and colleagues ${ }^{19}$ discusses details of gastric tube construction associated with the incidence of impaired gastric mobility and also concludes that a pyloric drainage procedure performed at the time of esophagectomy did not have a statistically significant effect on the incidence of delayed gastric emptying. Although our report is a small retrospective case series, the study demonstrates the feasibility of conduit revision in this patient population and allows others to learn from our successes and mistakes.

\section{CONCLUSIONS}

Severe gastric conduit dysfunction after esophagectomy is rare. Symptoms, esophagram findings, and response to interventional esophagoscopy guide the decision to consider revising the conduit. Computed tomography imaging is essential in ruling out extrinsic factors leading to conduit dysfunction. Principles of conduit revision include revision of the anastomosis cephalad as needed, reducing paraconduit hernias when present, plication or stapled excision of dilated conduit, straightening an angulated conduit, and ensuring adequate gastric drainage. Conduit revision has been performed selectively with minimal morbidity and provides patients with durable improvement in symptoms of dysphagia and reflux.

\section{Conflict of Interest Statement}

Authors have nothing to disclose with regard to commercial support.

\section{References}

1. Maus MKH, Leers J, Herbold T, Bludau M, Chon SH, Kleinert R, et al. Gastric outlet obstruction after esophagectomy: retrospective analysis of the effectiveness and safety of postoperative endoscopic pyloric dilation. World J Surg. 2016;40:2405-11.

2. Eldaif SM, Lee R, Adams KN, Kilgo PD, Gruszynski MA, Force SD, et al. Intrapyloric botulinum injection increases postoperative esophagectomy complications. Ann Thorac Surg. 2014;97:1959-65.

3. Kim JH, Lee HS, Kim MS, Lee JM, Kim SK. Balloon dilatation of the pylorus for delayed gastric emptying after oesophagectomy. Eur J Cardiothorac Surg. 2008; 33:1105-11

4. Lanuti M, DeDelva P, Morse CR, Wright CD, Wain JC, Gaissert HA, et al. Management of delayed gastric emptying after esophagectomy with endoscopic balloon dilatation of the pylorus. Ann Thorac Surg. 2011;91:1019-24.

5. Oor JE, Wiezer MJ, Hazebroek EJ. Hiatal hernia after open versus minimally invasive esophagectomy: a systematic review and meta-analysis. Ann Surg Oncol. 2016;23:2690-8.

6. Ganeshan DM, Correa AM, Bhosale P, Vaporciyan AA, Rice D, Mehran RJ, et al. Diaphragmatic hernia after esophagectomy in 440 patients with long-term follow-up. Ann Thorac Surg. 2013;96:1138-45. 
7. Price TN, Allen MS, Nichols FC, Cassivi SD, Wigle DA, Shen KR, et al. Hiatal hernia after esophagectomy: analysis of 2,182 esophagectomies from a single institution. Ann Thorac Surg. 2011;92:2041-5.

8. Kent MS, Luketich JD, Tsai W, Churilla P, Federle M, Landreneau R, et al. Revisional surgery after esophagectomy: an analysis of 43 patients. Ann Thorac Surg. 2008;86:975-83.

9. Burt M, Scott A, Williard WC, Pommier R, Yeh S, Bains MS, et al. Erythromycin stimulates gastric emptying after esophagectomy with gastric replacement: a randomized clinical trial. J Thorac Cardiovasc Surg. 1992;102:391-4.

10. Simpson PJ, Ooi C, Chong J, Smith A, Baldey A, Staples M, et al. Does the use of nizatidine, as a pro-kinetic agent, improve gastric emptying in patients post-oesophagectomy? J Gastrointest Surg. 2009;13:432-7.

11. Datta J, Williams NN, Conway G, Dempsey DT, Morris JB. Rescue pyloroplasty for refractory delayed gastric emptying following esophagectomy. Surgery. 2014; 156:290-7.

12. Asti E, Lovece A, Bonavina L. Thoracoscopic implant of neurostimulator for delayed gastric conduit emptying after esophagectomy. J Laparoendosc Adv Surg Tech A. 2016;26:299-301.

13. Salameh JR, Aru GM, Bolton W, Abell TL. Electrostimulation for intractable delayed emptying of intrathoracic stomach after esophagectomy. Ann Thorac Surg. 2008;85:1417-9.

14. D'Journo XB, Martin J, Gaboury L, Ferraro P, Duranceau A. Roux-en-Y diversion for intractable reflux after esophagectomy. Ann Thorac Surg. 2008;86:1646-52.

15. Yano M, Motoori M, Tanaka K, Kishi K, Miyashiro I, Shingai T, et al. Prevention of gastroduodenal content reflux and delayed gastric emptying after esophagectomy: gastric tube reconstruction with duodenal diversion plus Roux-en-Y anastomosis. Dis Esophagus. 2012;25:181-7.

16. Varghese TK, Hofstetter WL, Rizk NP, Low DE, Darling GE, Watson TJ, et al. The Society of Thoracic Surgeons guidelines on the diagnosis and staging of patients with esophageal cancer. Ann Thorac Surg. 2013;96:346-56.

17. Ajani JA, Barthel JS, Bentrem DJ, D'Amico TA, Das P, Denlinger CS, et al. Esophageal and esophagogastric junction cancers. J Natl Compr Canc Netw. 2011;9:830-87.

18. Puri V, Hu Y, Guthrie T, Crabtree TD, Kreisel D, Krupnick AS, et al. Retrograde jejunogastric decompression after esophagectomy is superior to nasogastric drainage. Ann Thorac Surg. 2011;92:499-503.

19. Akkerman RDL, Haverkamp L, van Hillegersberg R, Ruurda JP. Surgical techniques to prevent delayed gastric emptying after esophagectomy with gastric interposition: a systematic review. Ann Thorac Surg. 2014;98: 1512-9.

20. Bemelman WA, Taat CW, Slors JF, Van Lanschot JJ, Obertop H. Delayed posteroperative emptying after esophageal resection is dependent on the size of the gastric substitute. J Am Coll Surg. 1995;180:461-4.

21. Burrows WM. Gastrointestinal function and related problems following esophagectomy. Semin Thorac Cardiovasc Surg. 2004;16:142-51.

Key Words: complications, delayed gastric emptying, esophageal cancer, esophagectomy, gastric conduit, pyloroplasty, pylorus

Readers who found these articles interesting may also like to read the following papers found in recent and future issues of our sister publications, Seminars in Thoracic and Cardiovascular Surgery and Operative Techniques in Thoracic and Cardiovascular Surgery!

\section{Thoracic: Esophagus}

ORIGINAL SUBMISSION: Black and White Esophagus: Rare Presentations of Severe Esophageal Ischemia. Daniel B. Kim. Semin Thoracic Surg 2017: In press.

Editorial Commentary: Black Esophagus, White Esophagus, or Shades of Gray? Justin D. Blasberg. Semin Thoracic Surg 2017: In press.

STATE OF THE ART: The State of The Art in Per-Oral Endoscopic Myotomy. Stavros N. Stavropoulos. Semin Thoracic Surg 2016: $137-146$. 